\title{
EXPERIMENTAL AND NUMERICAL INVESTIGATION OF V-SHAPED EPOXY ADHESIVE JOINTS
}

\author{
Mohd Afendi ${ }^{1, *}$, Nur Athirah ${ }^{1}$, M.S. Abdul Majid ${ }^{1}$, R. Daud ${ }^{1}$ and Tokuo Teramoto ${ }^{2}$ \\ ${ }^{1}$ School of Mechatronic Engineering, Universiti Malaysia Perlis, 02600, Arau, Perlis \\ Phone : +604-9885162; Fax :+604-9885167 \\ *Email: afendirojan@ unimap.edu.my \\ ${ }^{2}$ Graduate School of Systems and Information Engineering, \\ University of Tsukuba, 305-0821, Tsukuba, Japan
}

\begin{abstract}
This paper deals with the stress and failure characteristics of $\mathrm{V}$-shaped epoxy adhesive joints. The effect of scarf angles upon failure morphology was investigated by tensile tests and monitoring using high speed cameras. V-shaped specimens were fabricated with three bond thicknesses, $t$ (i.e. $0.2 \mathrm{~mm}, 0.6 \mathrm{~mm}$, and $1.0 \mathrm{~mm}$ ) and various scarf angles (i.e. $\theta=30^{\circ}, 45^{\circ}, 60^{\circ}, 75^{\circ}$, and $90^{\circ}$ ). From failure surface observation, failure morphology can be divided into five types, consisting of interface failure and/or cohesive failure. Shear stress plays a major role in failure morphology where higher shear stress favors interface failure in the specimens tested. A simple failure criterion is also proposed based on the results obtained. It is found that the proposed criterion can approximately predict the failure stress of $\mathrm{V}$-shaped epoxy adhesive joint specimens. For stress analysis, $\mathrm{V}$-shaped epoxy adhesive joints having bond thicknesses $t=1.0 \mathrm{~mm}$, and with various scarf angles (i.e. $\theta=30^{\circ}, 45^{\circ}, 60^{\circ}, 75^{\circ}$, and $90^{\circ}$ ), were modelled. Stress singularity observed in simulation plays a major role in failure morphology where higher singularity favors cohesive failure in the specimens tested in experiment.
\end{abstract}

Keywords: V-shaped; adhesive joint; bond thickness; scarf angle; failure criterion; finite element.

\section{INTRODUCTION}

Adhesive bonding is an important technique that has been used since ancient times. It is now being used widely in construction and industrial structures, etc(Bachtiar, Sapuan, \& Hamdan, 2010; Ravi Sankar, Srikant, Vamsi Krishna, Bhujanga Rao, \& Bangaru Babu, 2013). The exploitation of composite materials and adhesives has greatly increased because they offer lighter, more compact and higher performance structures. Adhesive bonding has various benefits: it covers a wide range of joins, and has the ability to join very thin sheet and small parts. With the application of adhesive bonding, the improvement of products and production processes also becomes possible (Jeffrey, Tarlochan, \& Rahman, 2011; Salleh, Yusop, \& Rosdi, 2013). However, adhesive bonding also has disadvantages, such as limited heat resistance and impossibility of non-destructive testing. Adhesive bonding is definitely an important parameter in structural design. It also has a significant impact on the reliability of a structure. It is therefore crucial to understand the influence of adhesives upon strength properties of bonded structures. 
In previous studies, fracture testing of adhesive joints has been conducted using a room temperature curing two-part epoxy adhesive resin, which is widely used in general. Tensile tests were conducted by varying the thickness of adhesive layer and scarf angle, where a significant effect on fracture stress and the morphology of adhesive joint was revealed (Afendi \& Teramoto, 2009, 2010; Afendi, Teramoto, \& Bakri, 2011; Afendi, Teramoto, \& Matsuda, 2011). In addition, experimental and numerical evaluation of scarf adhesive joints subjected to static loading has been discussed (He, Sawa, Iwamoto, \& Hirayama, 2010). Nevertheless, less attention has been paid to investigating the strength of double scarf (also referred as V-shaped) adhesive joints, which thus motivates this study. In this study, tensile test specimens of V-shaped adhesive joints were manufactured using stainless steel as adherents. In comparison to scarf joints, $\mathrm{V}$-shaped adhesive joints have relatively less eccentricity of effect. Tensile testing was carried out to investigate the effect of scarf angle and bond thickness upon strength properties, to examine the relationship between strength and fracture morphology, and to establish the fracture criterion involved. Meanwhile, stress analysis was conducted using finite element software to examine the relationship between stress distribution within adhesive layers and failure morphology.

\section{EXPERIMENTAL PROCEDURES}

In this study, a two-part room temperature curing epoxy adhesive resin (Hi-Super 30, produced by Cemedine, Co., Japan) was used. A V-shaped adhesive joint specimen was made of stainless steel (i.e. SUS304). Figure 1 shows the dimensions of the specimen. The mechanical properties of the materials are given in Table 1. The bonding surface was polished with sandpaper, so that the surface roughness was uniform for each specimen. The bond thickness, $t$ was adjusted using a special jig ( $t=0.2 \mathrm{~mm}, 0.6 \mathrm{~mm}$, and $1.0 \mathrm{~mm}$ ). Various scarf angles, and $\theta$ were also considered (i.e. $\theta=30^{\circ}, 45^{\circ}, 60^{\circ}$, $75^{\circ}$, and $90^{\circ}$ ). All specimens were cured at room temperature for more than 24 hours. After the specimens were totally cured, excessive adhesive was removed using a portable grinder and a sharp knife. The actual bond thickness, $t$ was then measured with a digital microscope. The tensile test of the $\mathrm{V}$-shaped specimen was conducted at room temperature using a universal testing machine (INSTRON) with $0.5 \mathrm{~mm} / \mathrm{min}$ crosshead speed, and $10 \mathrm{kN}$ maximum load. A summary of the experimental conditions is given in Table 2. Load and displacement were measured up to the failure point. Tensile tests were carried out at least eight times for each condition. In addition, some experiments on specimens with pre-mounted strain gauge were performed. During the experiments, failure paths were observed using a high speed camera. After the testing, failure surfaces was observed using a digital microscope and their failure morphology and pattern were recorded.

\section{NUMERICAL ANALYSIS}

Stress distribution in adhesive layers and bonding interfaces was analyzed using finite element analysis (FEA) ANSYS software. By taking advantage of symmetrical features on the y-axis, a half FEA model was considered, as shown in Figure 2. Adhesive bond thickness, $t$ was $1.0 \mathrm{~mm}$. A two-dimensional FEA model had a width of $20 \mathrm{~mm}$ and height of $160 \mathrm{~mm}$. Various scarf angles were also modelled. In all simulations, a tensile stress of $1 \mathrm{MPa}$ was applied in the $y$-direction on all nodal points at both ends of adherents. As for the prescribed boundary conditions, all nodal points at $x$-direction 
were constrained. Stress values along bonding interfaces (i.e. $\xi_{1}$ and $\xi_{3}$ ) and at the center of the adhesive layer, $\xi_{2}$ were recorded, S and L were distance and interface length, respectively. A summary of the simulation conditions is given in Table 3.

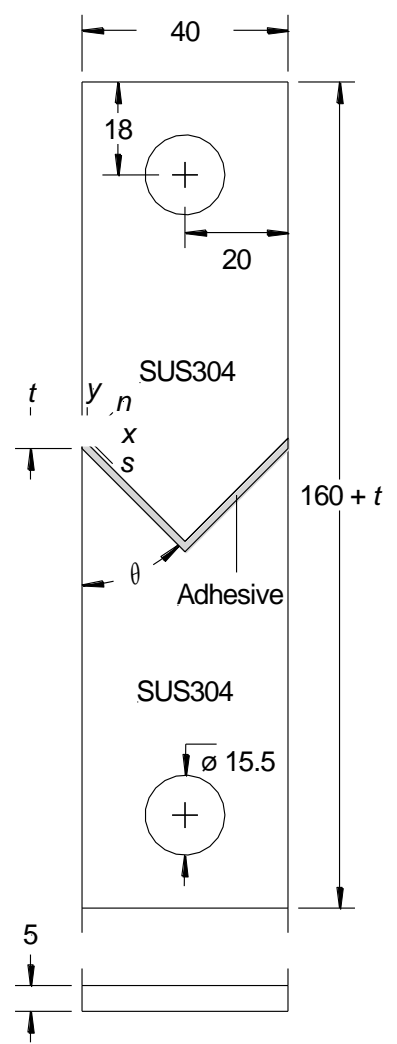

Figure 1. Geometry of V-shaped epoxy adhesive joint specimen.

Table 1. Mechanical properties of materials.

\begin{tabular}{lccc}
\hline \multicolumn{1}{c}{ Material } & $\begin{array}{c}E \text { (Eitssayeam, Intatha, Rujijanagul, Pengpat, \& } \\
\text { Tunkasiri, 2006) }\end{array}$ & $\sigma_{\mathrm{y}}(\mathrm{MPa})$ & $v$ \\
\hline $\begin{array}{l}\text { Epoxy } \\
\text { adhesive }\end{array}$ & 3.4 & $\begin{array}{l}34.76 \\
(1.67)\end{array}$ & 0.39 \\
\hline SUS304* & 197 & 307.8 & 0.3 \\
& & $(6.02)$ & \\
\hline & $*$ data taken from manufacturer's catalogue; ( ) denotes the value of standard deviation.
\end{tabular}

Table 2. Experimental condition.

\begin{tabular}{ll}
\hline \multicolumn{1}{c}{ Parameter } & \multicolumn{1}{c}{ Value } \\
\hline Adhesive angle, $\theta$ (degree) & $90,75,60,45,30$ \\
Bond thickness, $t(\mathrm{~mm})$ & $1.0,0.6,0.2$ \\
Number of specimen, $n$ & 8 \\
Experimental temperature & Room temperature \\
Crosshead speed $(\mathrm{mm} / \mathrm{min})$ & 0.5 \\
Maximum load $(\mathrm{kN})$ & 10 \\
\hline
\end{tabular}




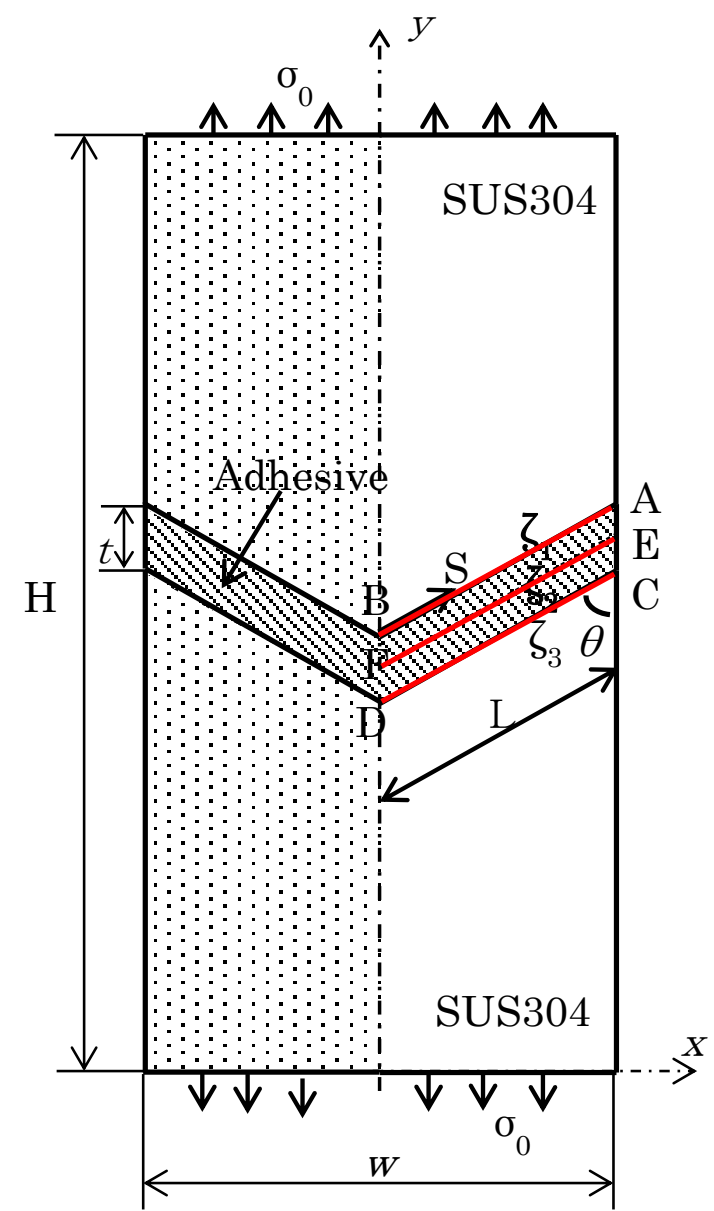

Figure 2. FEA half model.

Table 3. Simulation condition.

\begin{tabular}{ll}
\hline \multicolumn{1}{c}{ Parameter } & \multicolumn{1}{c}{ Value } \\
\hline Adhesive angle, $\theta$ (degree) & $90,75,60,45,30$ \\
Bond thickness, $t(\mathrm{~mm})$ & 1.0 \\
Width, $w(\mathrm{~mm})$ & 20 \\
Height, $H(\mathrm{~mm})$ & 160 \\
\hline
\end{tabular}

\section{RESULTS AND DISCUSSION}

The nominal stress and normal stress in the V-shaped adhesive joints, having a bond thickness of $1.0 \mathrm{~mm}, 0.6 \mathrm{~mm}$, and $0.2 \mathrm{~mm}$ with regard to the variation of scarf angle, are shown in Figures 3 and 4, respectively. It is understood from Figure 3 that the smaller the bond thickness, the greater the fracture stress. In addition, it is clear that the $y$ direction stress increases as scarf angle becomes smaller. In contrast, the smaller the scarf angle, the more normal stress is decreased, as can be appreciated from Figure 4. It is believed that when the scarf angle becomes more acute, the stress in the $y$-direction will increase due to the increased bonding area.

In addition, the failure surface of a specimen is more prone to interface failure when a scarf angle becomes more acute. The results also showed that specimens with a scarf angle closer to $90^{\circ}$ fail cohesively. In general, adhesive joints with cohesive failure 
have greater strength than those with interface failure. In this experiment, with regard to normal stress, when scarf angle was closer to $90^{\circ}$ the interface failure as well as strength were increased. Since this experiment also showed a similar trend, it can be concluded that good results were obtained.

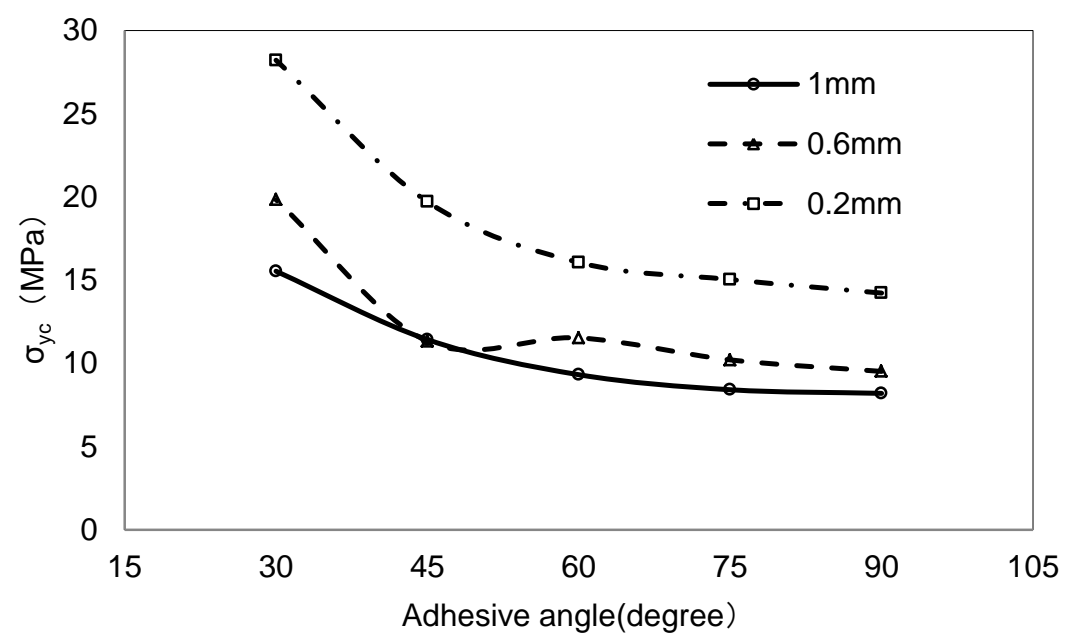

Figure 3. Nominal stress against scarf angle.

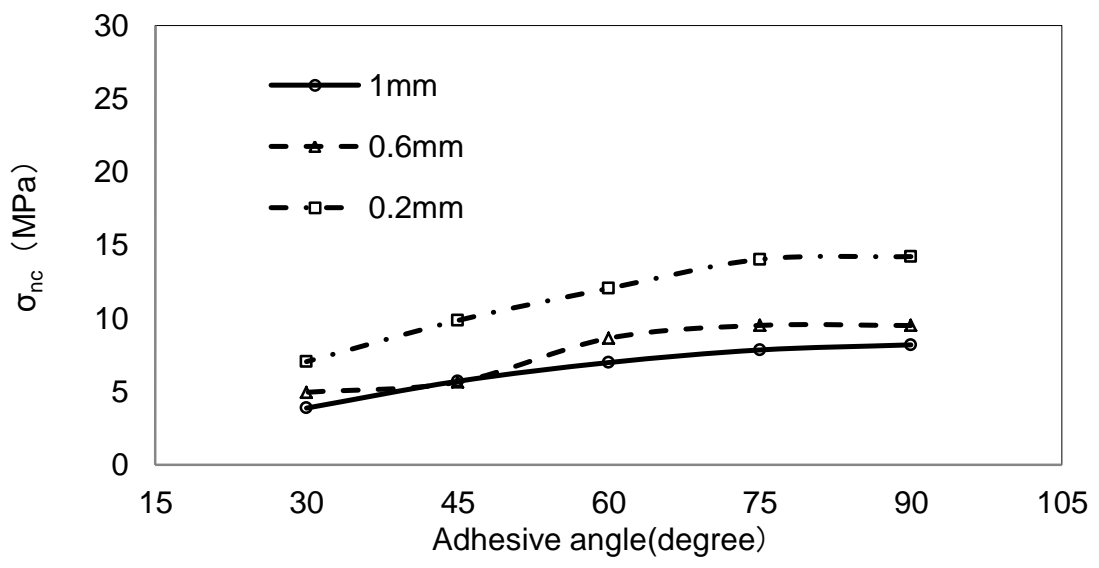

Figure 4. Normal stress against scarf angle.

Figure 5 shows the shear stress in the adhesive joint with regard to variation of scarf angle. It is also confirmed that the smaller the thickness of the adhesive layer, the higher the strength. In addition, in each bond thickness, the shear stress is increased if the scarf angle becomes more acute. When the scarf angle is more acute, the shear stress will increase and interface failure is likely to occur. Therefore, shear stress is thought to be a dominant factor in interfacial failure.

Failure criterion was then estimated from the experimental results. First, stress normal to the direction of the adhesive layer of the specimen at failure, and shear stress at failure are defined as $\sigma_{\mathrm{nc}}$ and $\tau_{\mathrm{snc}}$, respectively. Therefore,

$$
\sigma_{n c}=\sigma_{y c} \sin \theta, \tau_{s n c}=\sigma_{y c} \sin \theta \cos \theta
$$

are defined. Thus, from the relation between $\sigma_{\mathrm{nc}}$ and $\tau_{\mathrm{snc}}$, 


$$
{\sigma_{n c}}^{2}+\tau_{s n c}{ }^{2}=\text { const }
$$

can be derived. Here, the shape of the specimen in the following relationship is considered

$$
\sigma_{y}{ }^{\prime} L=\sigma_{y} W
$$

where, $\sigma_{\mathrm{y}}$, is the $y$-direction stress along the adhesive layer, $\sigma_{\mathrm{y}}$ is the nominal stress, $L$ is the length of the adhesive layer, and $W$ represents the width of the model. From Eqs. (2) and (3), the following relationship is then derived.

$$
\sigma_{y c}{ }^{\prime}=\sigma_{y} \frac{W}{L}=\sigma_{y} \sin \theta=\text { const }
$$

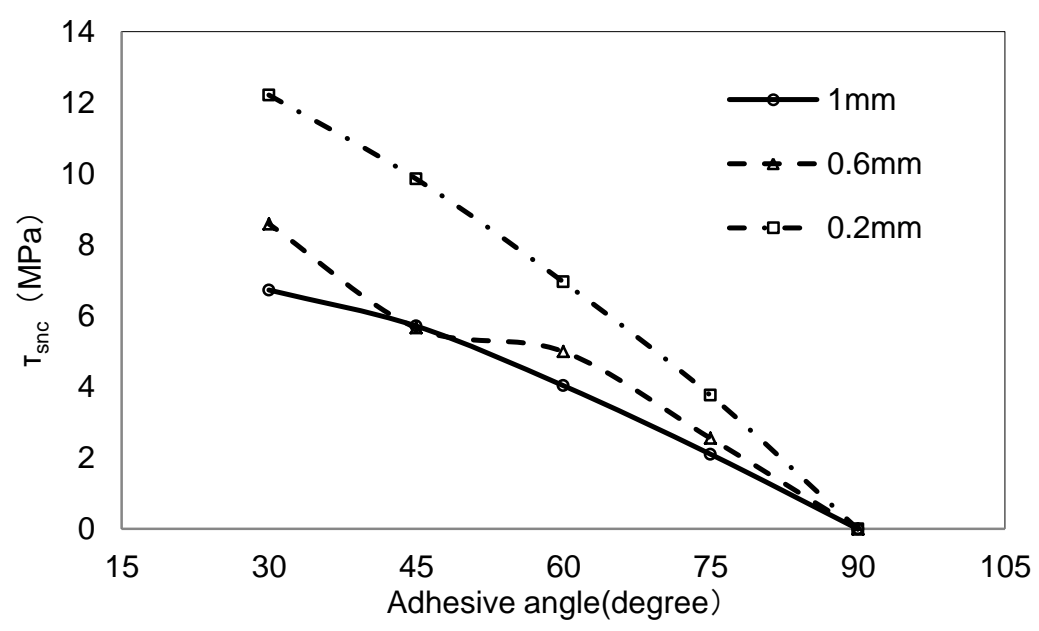

Figure 5.Shear stress against scarf angle.

Figure 6 shows the relationship between $\sigma_{\mathrm{yc}}$ and $t$ obtained in this study. From this result, it was observed that failure stress in the $y$-direction along the adhesive layer, $\sigma_{\mathrm{yc}}$ is exponentially proportional to the bond thickness, $t$ which can be expressed as follows

$$
\sigma_{y c}{ }^{\prime}=m t^{n}
$$

Here, $m$ and $n$ are constants which can be determined experimentally. The failure criterion expression of this experiment through power regression of line in Figure 6,

$$
\sigma_{y c}{ }^{\prime}=8.05 t^{-0.35}
$$

is now derived. From this form of failure criterion expression, for the particular material and shape geometry used in this investigation, it is considered that the failure can be roughly predicted. This can be seen in Figure 7 where the experimental data is in good agreement with the respective prediction lines. Thus, it can be concluded that for Vshaped adhesive joints, a simple failure criterion as in Eq. (6) is obtained. 
Representatives of failure type and morphology observed from the specimen tests are given in Table 5. Basically, failure of specimens can be divided into five patterns: $100 \%$ interface failure, interface failure transition, cohesive-interface transition, rough cohesive failure and $100 \%$ cohesive failure. Interface failure is likely to occur in joint specimens with smaller scarf angles while cohesive failure is in higher scarf angles. This can be related to the contribution of shear stress within the joint specimen. The higher the shear stress component, the greater the possibility for interface failure to occur. Table 6 shows the representative failure surface for each scarf angle. It can be seen here that for $30^{\circ}$ and $45^{\circ}$, interface or interface transition failures are dominant. However, for $60^{\circ}, 75^{\circ}$ and $90^{\circ}$, cohesive-interface transition and rough/pure cohesive failures are mostly observed. It is noteworthy that failure morphology also changes with bond thickness. For thin bond thickness, $t=0.2 \mathrm{~mm}$, a higher percentage of cohesive failure has been observed. This can be attributed to the increment of shear stress component in a thin adhesive layer.

Table 4. Value of $\sigma_{\mathrm{yc}}$, for strength prediction.

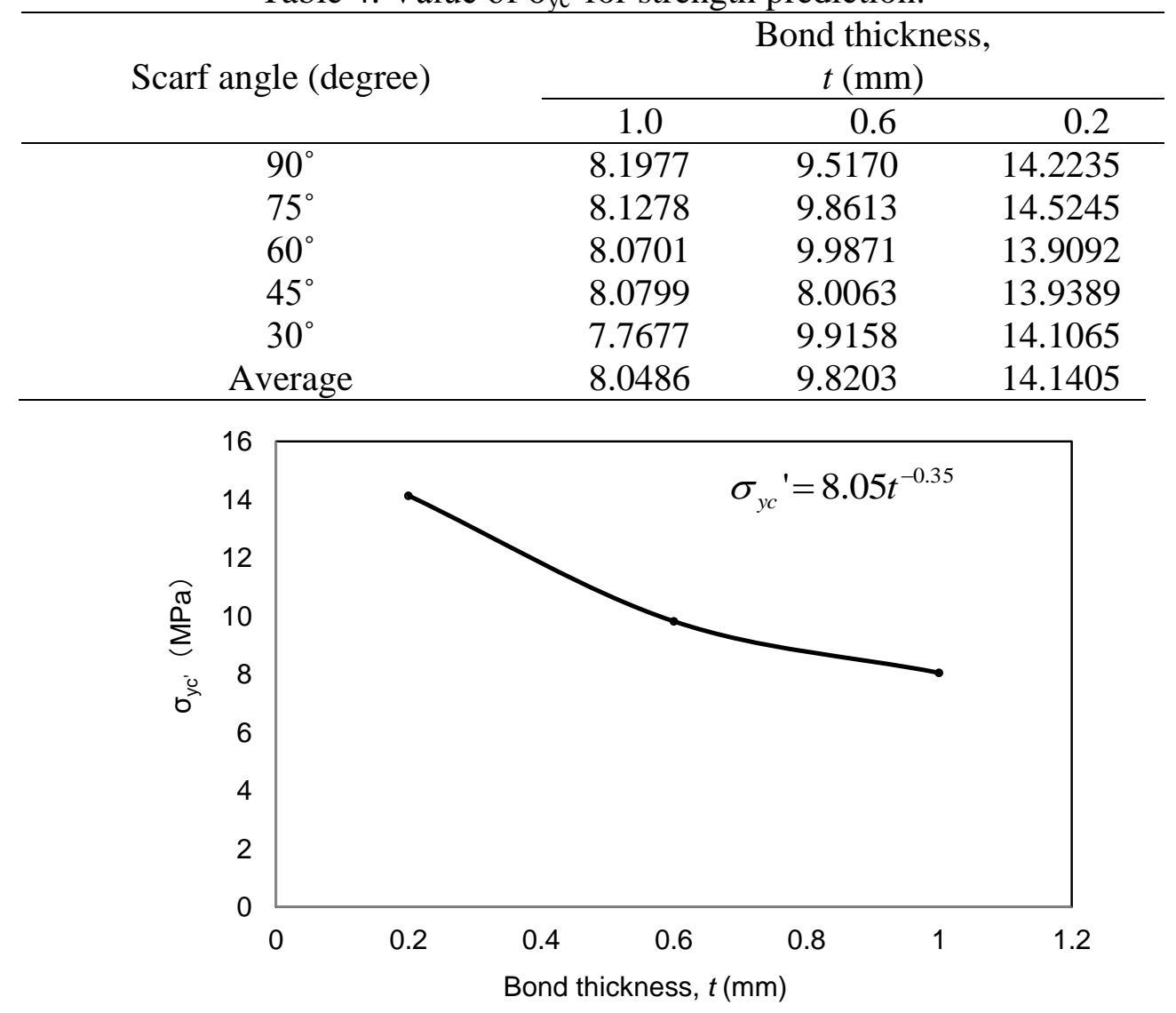

Figure 6. Failure stress-bond thickness prediction diagram.

From Figure 8, it can be seen that if scarf angle becomes slanted, bonding interface stress will be reduced. Moreover, stress singularity can be seen in models with $90^{\circ}$ and $75^{\circ}$ scarf angles. Stress singularity at bonding interfaces should therefore be considered. It has been reported that $90^{\circ}, 75^{\circ}$ and $30^{\circ}$ joints will produce stress singularity, but for $45^{\circ}$ and $60^{\circ}$ joints, this singularity is significantly decreased. Theoretically, singularity in a $45^{\circ}$ joint is relatively small. Due to this, a crack has great likelihood of originating either at tip B or edge C. Eventually, both cracks have great 
potential to originate either at tip B or edge C. Eventually, both cracks will possibly intersect in the middle of the adhesive layer as can been seen in Figure 9 (a) which results in an interface transition type of failure. This can be appreciated by considering stress distribution in the specimen shown in Figure 9 (b). It is obvious that stress is high at tip $B$ and edge C. Figure 10 shows applied load against strain for a $45^{\circ}$ joint having three strain gages mounted. It is confirmed from the highest strain recorded from strain gage 2 that a crack has initiated at tip $B$ and succeeded by edge $C$.

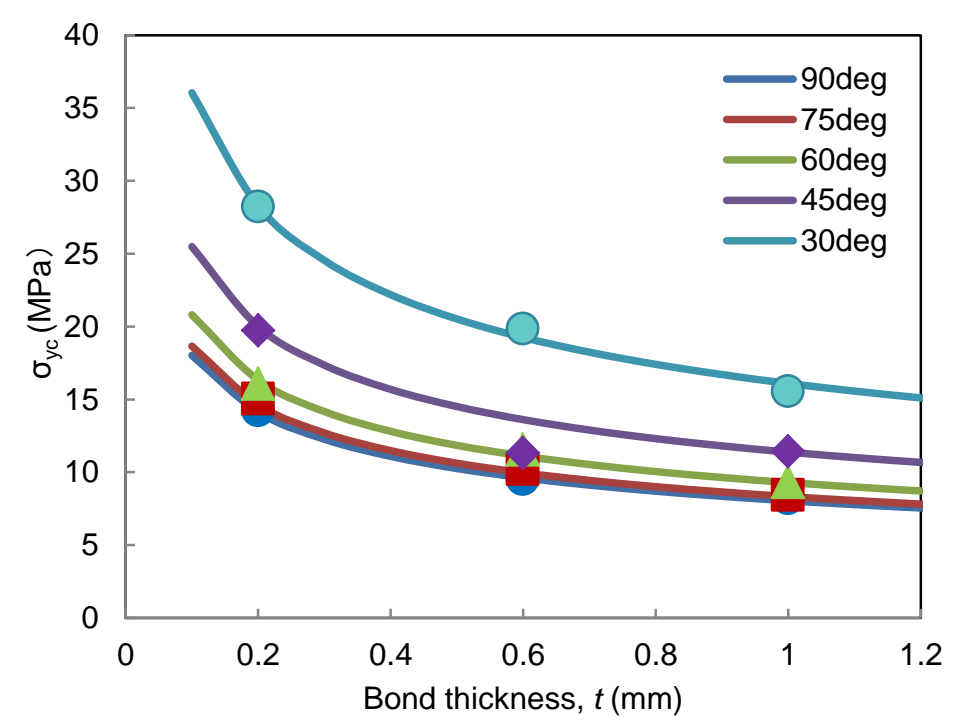

Figure 7. Joint strength prediction for various scarf angles.

Table 5. Failure type and morphology.

\begin{tabular}{|c|c|c|c|c|c|}
\hline $\begin{array}{c}\text { Failure } \\
\text { type }\end{array}$ & I. IF & $\begin{array}{c}\text { II. IF } \\
\text { Transition }\end{array}$ & $\begin{array}{l}\text { III. CF-IF } \\
\text { Transition }\end{array}$ & $\begin{array}{l}\text { IV. Rough } \\
\text { CF }\end{array}$ & V. CF \\
\hline $\begin{array}{l}\text { Failure } \\
\text { path }\end{array}$ & & & & & \\
\hline $\begin{array}{l}\text { Side } \\
\text { view }\end{array}$ & & & & & \\
\hline Top view & & & & (2) & \\
\hline
\end{tabular}

Table 6.Scarf angle and failure morphology.

\begin{tabular}{|c|c|c|c|c|c|}
\hline $\begin{array}{l}\text { Scarf } \\
\text { angle }\end{array}$ & $30^{\circ}$ & $45^{\circ}$ & $60^{\circ}$ & $75^{\circ}$ & $90^{\circ}$ \\
\hline
\end{tabular}



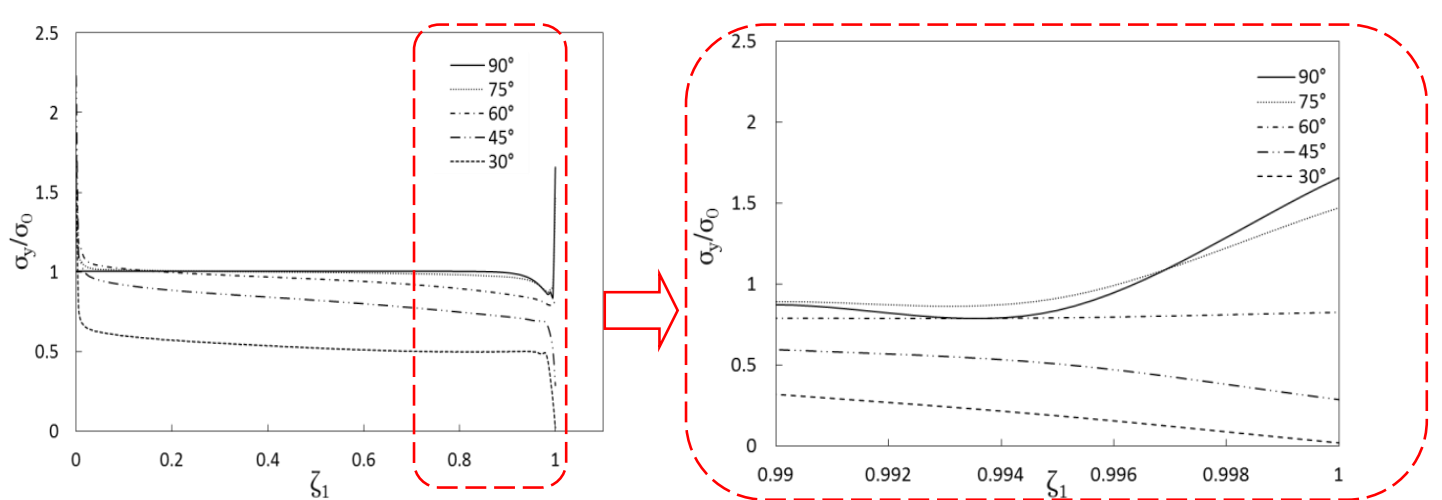

(a)
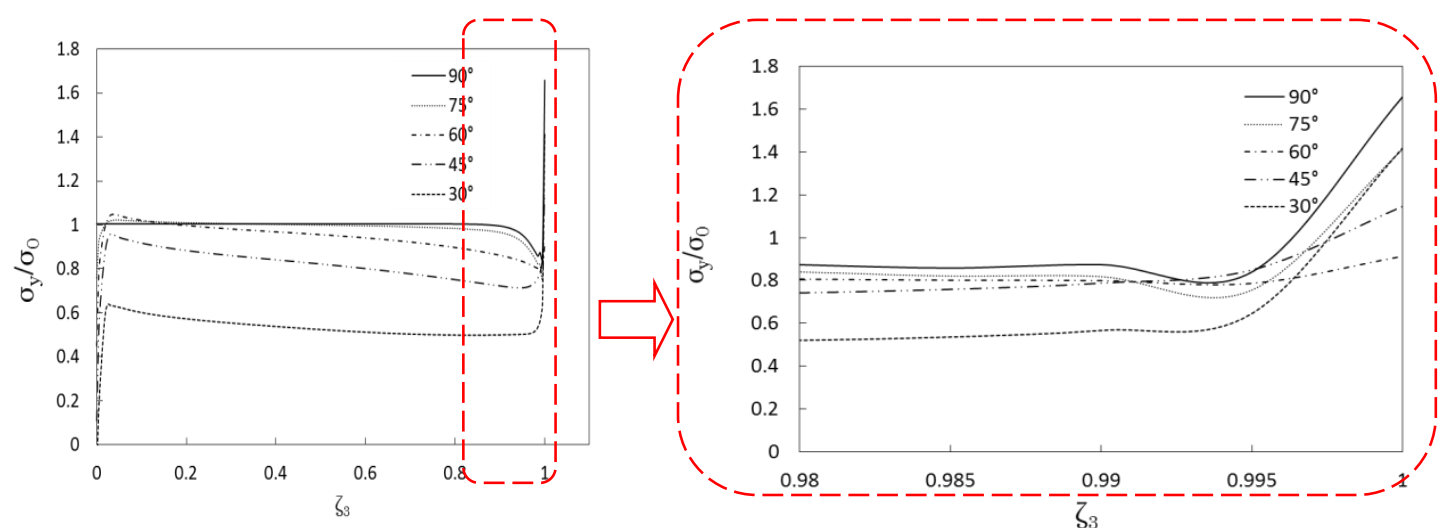

(b)

Figure 8. Stress distribution at (a) upper; (b) lower bonding interfaces.

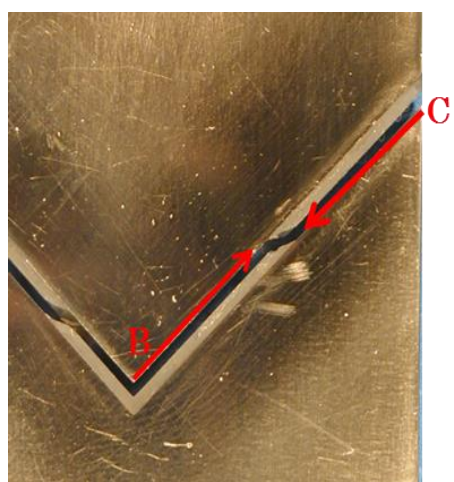

(a)

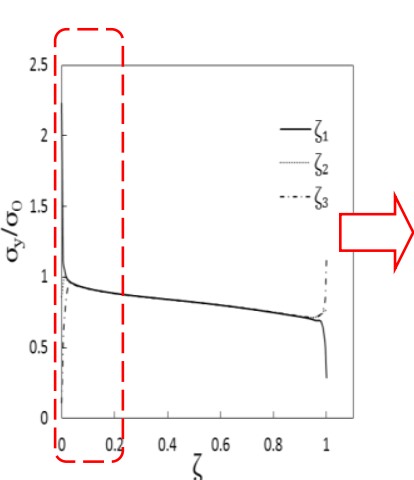

(b)

Figure 9. Crack initiation and direction of propagation in $45^{\circ}$ specimen. (a) crack path; (b) stress distribution. 


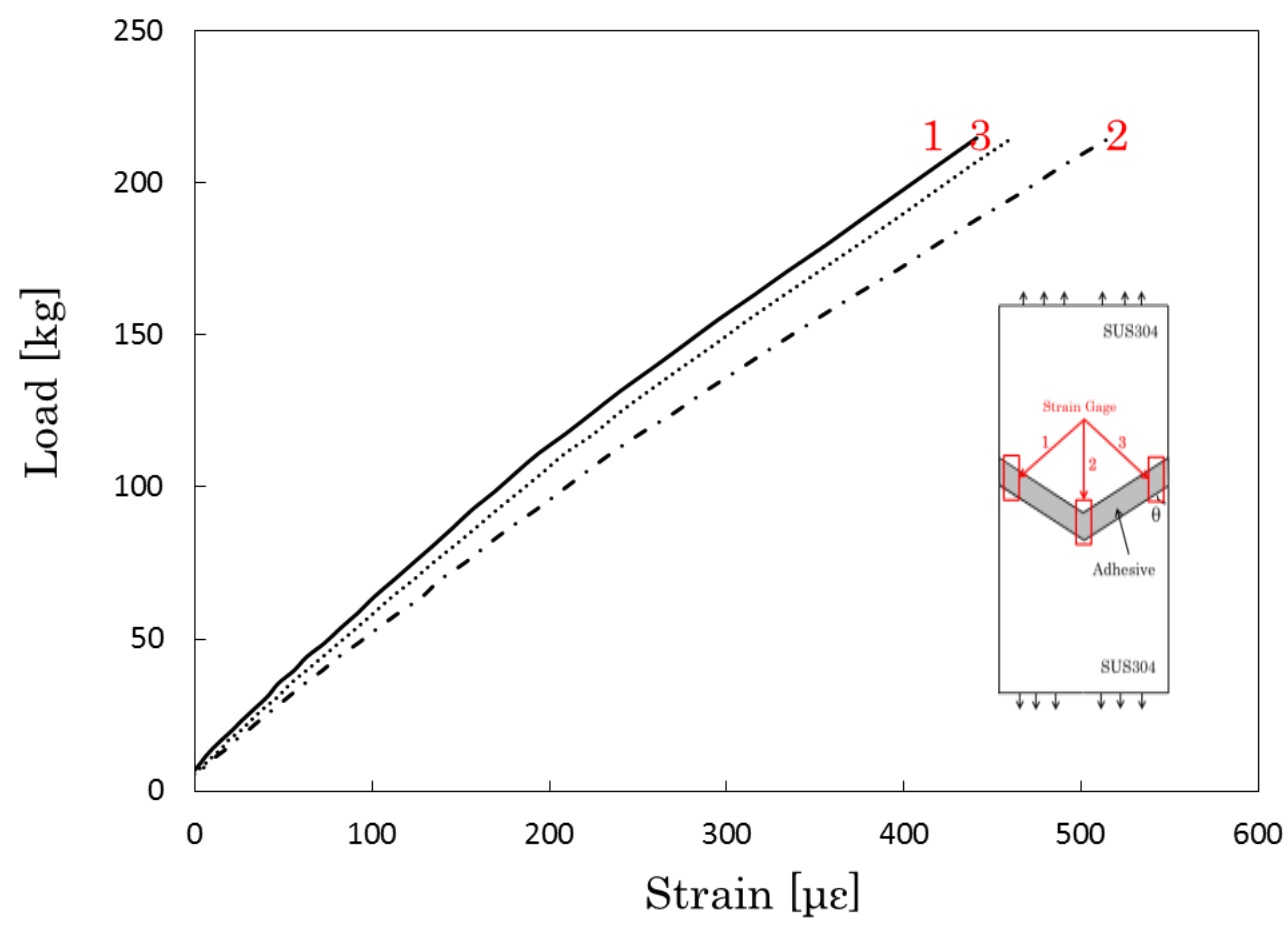

Figure 10. Applied load versus strain for $45^{\circ}$ specimen.

\section{CONCLUSIONS}

In this study, tensile tests were conducted on V-shaped epoxy adhesive joints having various scarf angles and bond thicknesses. Stress analysis was conducted on V-shaped epoxy adhesive joints of $1.0 \mathrm{~mm}$ bond thickness with various scarf angles. According to experimental findings, failure stress is greater when the bond thickness is reduced. The direction of the normal stress showed the same tendency as the interface strength properties. Failure morphology can be divided into 5 types, consisting of IF and/or CF. When scarf angle becomes slant, failure morphology changes from $\mathrm{CF}$ into IF transition. Failure is governed by the shear stress and strength of specimens which failed, as cohesive failure is greater than those with interfacial failure. Moreover, failure is more dependent on the bond thickness than the scarf angle of V-shaped adhesive joint. For joint strength prediction, a simple failure criterion for $\mathrm{V}$-shaped adhesive joint is proposed and it has considerable potential. The FEA results confirm that cracks will originate at the tip or edge with higher stress singularity. Crack propagation paths depend on stress distribution at interfaces and inside the adhesive layer. It can also be concluded that stress distribution at interfaces and inside the adhesive layer determines the observed failure morphology.

\section{REFERENCES}

Afendi, M., \& Teramoto, T. (2009). Effect of bond thickness on fracture behavior of interfacial crack in adhesive joint of dissimilar materials. Journal of The Adhesion Society of Japan, 45, 471-476. 
Afendi, M., \& Teramoto, T. (2010). Fracture toughness test of epoxy adhesive dissimilar joint with various adhesive thicknesses. Journal of Solid Mechanics and Materials Engineering, 4(7), 999-1010.

Afendi, M., Teramoto, T., \& Bakri, H. B. (2011). Strength prediction of epoxy adhesively bonded scarf joints of dissimilar adherends. International Journal of Adhesion and Adhesives, 31(6), 402-411.

Afendi, M., Teramoto, T., \& Matsuda, A. (2011). Strength and fracture characteristics of sus304/al-alloy scarf adhesive joint with various adhesive thicknesses. Key Engineering Materials, 462, 768-773.

Bachtiar, D., Sapuan, S. M., \& Hamdan, M. M. (2010). Flexural properties of alkaline treated sugar palm fibre reinforced epoxy composites. International Journal of Automotive and Mechanical Engineering, 1, 79-90.

Eitssayeam, S., Intatha, U., Rujijanagul, G., Pengpat, K., \& Tunkasiri, T. (2006). Structural and electrical properties characterization of (1-x) pbzr0. 52ti0. 48o3xbafe0. 5nb0. 503 system. Applied Physics A, 83(2), 295-299.

He, D., Sawa, T., Iwamoto, T., \& Hirayama, Y. (2010). Stress analysis and strength evaluation of scarf adhesive joints subjected to static tensile loadings. International Journal of Adhesion and Adhesives, 30(6), 387-392.

Jeffrey, K. J. T., Tarlochan, F., \& Rahman, M. M. (2011). Residual strength of chop strand mats glass fiber/epoxy composite structures: Effect of temperature and water absorption. International Journal of Automotive and Mechanical Engineering, 4, 504-519.

Ravi Sankar, H., Srikant, R. R., Vamsi Krishna, P., Bhujanga Rao, V., \& Bangaru Babu, P. (2013). Estimation of the dynamic properties of epoxy glass fabric composites with natural rubber particle inclusions. International Journal of Automotive and Mechanical Engineering, 7, 968-980.

Salleh, Z., Yusop, M. Y. M., \& Rosdi, M. S. (2013). Mechanical properties of activated carbon (ac) coir fibers reinforced with epoxy resin. Journal of Mechanical Engineering and Sciences, 5, 631-638. 